\title{
Observations of multiple pelagic egg masses from small-sized jumbo squid (Dosidicus gigas) in the Gulf of California
}

\author{
Matthew A. Birk (D), Christopher Paight (D) and Brad A. Seibel \\ Department of Biological Sciences, University of Rhode Island, Kingston, RI, USA
}

\begin{abstract}
Egg masses of ommastrephid squids are rarely found and not well studied. For the Humboldt squid, Dosidicus gigas, only a single egg mass has been scientifically documented in the wild. Little is known about the size and spatial or temporal distribution of egg masses, or the number of eggs they contain. In this study, we report observations of six egg masses laid in the Gulf of California in May 2015. Egg mass diameters were two to four times smaller in this study compared with the previously observed mass reported in 2008, consistent with the small and large sizes, respectively, of mature female squid captured during each study. Each egg mass contained $17,000-90,000$ embryos, one to two orders of magnitude lower than that estimated for the large egg mass previously observed. Egg masses were observed at 9-14 m depth on or near a thermocline. Developmental stages of embryos and paralarvae differed between egg masses. No egg masses were observed in the 13 dives before or the four dives after these masses were found, suggesting that female spawning activity is probably spatially, or perhaps temporally, patchy. Developmental heterochronies in chromatophore development between $D$. gigas and other ommastrephid squids are discussed. Amphipods and ciliates infested the majority of masses, which is the first documented case of biota associated with wild ommastrephid egg masses.
\end{abstract}

\section{ARTICLE HISTORY}

Received 30 March 2016

Accepted 30 June 2016

\section{KEYWORDS}

Reproduction; embryo; ommastrephid; scaling; fecundity

\section{Introduction}

The jumbo squid, Dosidicus gigas (d'Orbigny, 1835), is among the largest squids, reaching $1.2 \mathrm{~m}$ in mantle length and $50 \mathrm{~kg}$ in mass (Jereb and Roper 2010). Female squids store mature eggs in the oviducts until spawning. When spawning a given egg mass, the eggs are mixed with nidamental gland jelly, fertilized and released as a gelatinous mass (Arkhipkin 1992).

The eggs of ommastrephid squids, such as $D$. gigas, have rarely been documented because they are found in oceanic environments where search effort by humans is

CONTACT Matthew A. Birk matthewabirk@gmail.com

Present address for Brad A. Seibel and Matthew A. Birk is College of Marine Science, University of South Florida, St. Petersburg, FL, USA.

(4) Supplemental material for this article can be accessed here: 
exceedingly sparse. Captive-spawned egg masses have been documented from Todarodes pacificus (Hamabe 1963; Bower and Sakurai 1996; Puneeta et al. 2015), Illex illecebrosus (Durward et al. 1980; O'Dor et al. 1982; O'Dor and Balch 1985), Illex coindetii (von Boletzky et al. 1973), Sthenoteuthis oualaniensis (Chesalin and Giragosov 1993) and Dosidicus gigas (Staaf et al. 2008). Observations of egg masses in the wild are more limited. Naef (1928) and Laptikhovsky and Murzov (1990) observed single egg masses for $I$. coindetii and Sthenoteuthis pteropus, respectively. O'Shea et al. (2004) observed nine egg masses from Nototodarus gouldi, while Staaf et al. (2008) observed a single egg mass from D. gigas. Due to the scarcity of these observations, the spatial and temporal distribution of ommastrephid female spawning events in the wild is poorly known.

The single egg mass of $D$. gigas observed to date as a free-floating jelly blob reached 3-4 $\mathrm{m}$ in diameter (Staaf et al. 2008) and was estimated to contain as many as 4 million eggs (Staaf et al. 2016). However, most ommastrephid squids are much smaller and, from limited observations, produce much smaller egg masses containing far fewer eggs (O'Dor and Balch 1985). Larger squids take longer to reach maturity than smaller squids, and therefore have a greater predation risk; but typically if they survive to maturation, they have a higher fecundity (Nigmatullin and Markaida 2009).

Interestingly, the size and age at maturity is plastic for $D$. gigas. Depending on the temperature regimen early in ontogeny, D. gigas either matures after just 1 year at a modal dorsal mantle length (DML) of $14-34 \mathrm{~cm}$ or after $1.5-2$ years at a much larger size of 55-120 cm (Arkhipkin et al. 2015). This provides an opportunity to observe the effects of body size and age at maturity on reproductive output.

We present observations of six D. gigas egg masses found in situ in 2015, when squid were found to be sexually mature at a small size in contrast to the larger squid reported in 2006 when the large egg mass was observed. We discuss the influence of female size at maturity on egg mass size and examine spatial and temporal variability and biota associated with these egg masses.

\section{Methods}

\section{Egg mass collection}

Egg masses were observed during three blue water SCUBA dives conducted on 28-30 May 2015 in Guaymas Basin, Gulf of California, Mexico $\left(27.25^{\circ} \mathrm{N}, 111.5^{\circ} \mathrm{W}\right.$, bottom depth $\approx 2000 \mathrm{~m}$ ) (Supplemental material 1) according to the practices of Haddock and Heine (2005). In total, 21 dives were conducted from 18 May to 1 June 2015 with an average duration of 40 minutes and a maximum depth of $20 \mathrm{~m}$. Eight of those dives were conducted at night around 20:00 to 21:00.

Photos of three egg masses, with a diver immediately behind for scale, were analysed for size using ImageJ (v.1.49o, Abràmoff et al. 2004). In addition, egg density was estimated for one egg mass using two methods. First, eggs were counted from $352 \mathrm{~cm}^{2}$ of an image to provide an estimate of egg density (Supplemental material 2). To convert from two-dimensional image area to three-dimensional egg mass volume, the depth of view in the image through the egg mass was assumed to be the average depth of a sphere with the egg mass's diameter. This technique was similar to that used by Bower and Sakurai (1996) for captively spawned T. pacificus egg masses. Second, for comparison to the density measurement 
technique used by Staaf et al. (2008) for a D. gigas egg mass, eggs were counted from four samples taken with collecting jars (2.84 I total).

Egg masses were sampled with $0.5-I$ and $1-I$ collecting jars, and eggs were subsequently examined under a Nikon SMZ1500 dissecting microscope aboard the ship within a few hours of collection. Eggs were staged according to Watanabe et al. (1996). The number of samples, and hence the number of eggs, collected from each egg mass varied. When hatched paralarvae were found, their mantle contraction rates were recorded under the microscope. Living amphipods and ciliates were also observed inside the egg mass samples. Some eggs and their associated biota were preserved in ethanol for later genetic analyses. In addition, adult female squid were captured using $11 \mathrm{~cm}$ hand jigs every night from 17 May to 1 June 2015. Maturity was assessed according to Nigmatullin and Markaida (2009).

Assuming the developmental rate in D. gigas is similar to another ommastrephid, T. pacificus, the spawning times of each egg mass were inferred as follows: the modal embryonic stage of each egg mass was identified. From these modes, the age of the egg mass was estimated according to the embryonic ages as identified by Watanabe et al. (1996) for $T$. pacificus developing at $20-23^{\circ} \mathrm{C}$. Two hours were subtracted from each estimate to account for the time between in situ sampling and embryonic stage identification. In support of the assumption that the two species have similar developmental rates, Watanabe et al. (1996) reported Stage 12 T. pacificus embryos 19.0 hours after fertilization $\left(17^{\circ} \mathrm{C}\right)$, which is within the time range described by Staaf et al. (2011) for $D$. gigas to reach the same stage $\left(18^{\circ} \mathrm{C}\right)$.

Although embryonic age estimates have been made for $D$. gigas by two previous studies (Yatsu et al. 1999; Staaf et al. 2011) ages for the embryos in the present study are very difficult to infer from either study. Neither paper reports developmental timing for any incubation temperature over $18^{\circ} \mathrm{C}$, much cooler than our embryos $\left(24-25^{\circ} \mathrm{C}\right)$. Additionally, Staaf et al. (2011) used large developmental stage categories (e.g. 'cleavage' and 'organogenesis') rather than the higher resolution stage 1-26 categories used by Watanabe et al. (1996). Yatsu et al. (1999) only reported ages for four stages that are late in embryogenesis (Stage 20-27) past all but one of the egg masses in our study.

A CTD cast (conductivity, temperature, depth; SeaBird) was conducted on the morning when the first egg mass was observed (28 May 2015; Figure 1). Daily sea surface temperature (SST) data were also collected from the Multi-scale Ultrahigh-Resolution SST data set (Chin et al. 2013) (Supplemental material 3).

\section{DNA extraction and polymerase chain reaction}

Samples were preserved in $100 \%$ ethanol. Samples were decanted and allowed to dry for $5 \mathrm{~min}$. $500 \mu \mathrm{l}$ of $3 \%$ CTAB solution (cetyltrimethyl ammonium bromide), $10 \mu \mathrm{l}$ of Proteinase $K$, and $1 \mu$ of $\beta$-mercaptoethanol were added to the samples. Samples were ground with a pestle and placed on a rotator for 1.5 hours at room temperature. DNA was phenol/chloroform extracted. Polymerase chain reaction (PCR) master mix was as follows: $17.4 \mu \mathrm{l}$ PCR grade water, $2.5 \mu \mathrm{l}$ buffer, $2 \mu \mathrm{l}$ dNTP, $1 \mu \mathrm{l}$ forward primer, $1 \mu \mathrm{l}$ reverse primer, $0.125 \mu \mathrm{l}$ Taq polymerase, $1 \mu \mathrm{l}$ DNA (Appendix; Clontech Laboratories, Inc., Mountain View, CA, USA). Samples were sequenced for COX1 in the squid eggs and $18 \mathrm{~S}$ in the amphipods and ciliates at the URI Sequencing Center. Sequences were identified using the NCBI web BLAST service (http://www.ncbi.nlm.nih.gov/). 


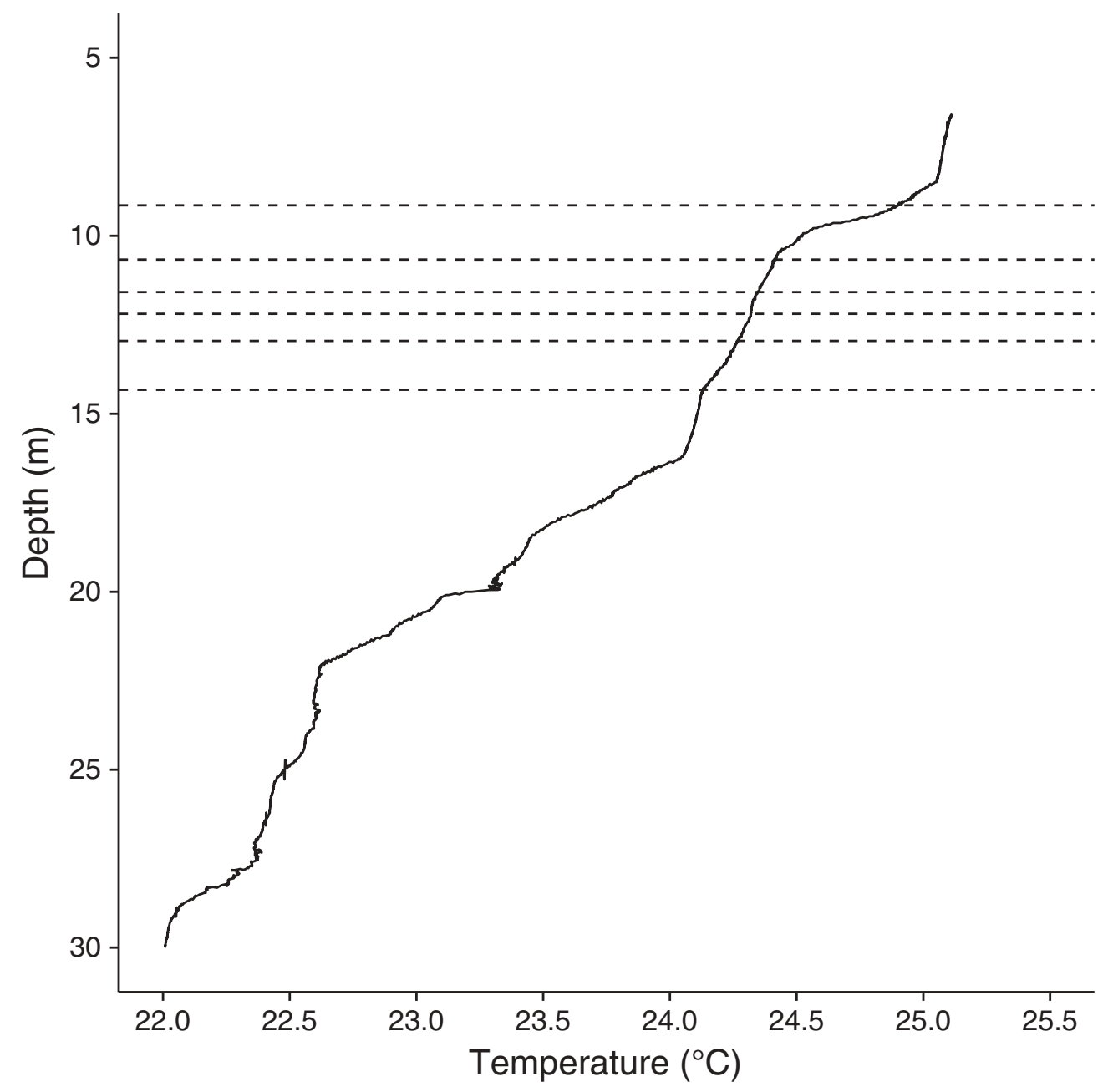

Figure 1. Conductivity, temperature, depth profile in the Gulf of California $\left(27.25^{\circ} \mathrm{N}, 111.5^{\circ} \mathrm{W}\right)$ on 28 May 2015. Horizontal dashed lines represent depth of egg masses.

\section{Results}

\section{Egg masses}

In total, six Dosidicus gigas egg masses were observed in situ on three dives over 3 days (Table 1). All egg masses were genetically confirmed to be D. gigas (COX1, 100\% sequence match). The first egg mass was observed at night on 28 May 2015 at approximately $14 \mathrm{~m}$ depth. Five other egg masses were observed during the daytime on 29 and 30 May 2015, between 9 and $14 \mathrm{~m}$ depth. These depths were on or between notable thermoclines and pycnoclines at $8 \mathrm{~m}$ and $16 \mathrm{~m}$ depth (Figure 1) such that the eggs were just below the $25^{\circ} \mathrm{C}$ isotherm.

The egg masses were spherical or oblong in shape. Photographs were available for three of the six egg masses. Estimated diameters from photographic analysis ranged from 69 to $141 \mathrm{~cm}$ (Table 2, Figure 2). Other masses were visually estimated by divers to be $30-100 \mathrm{~cm}$ 

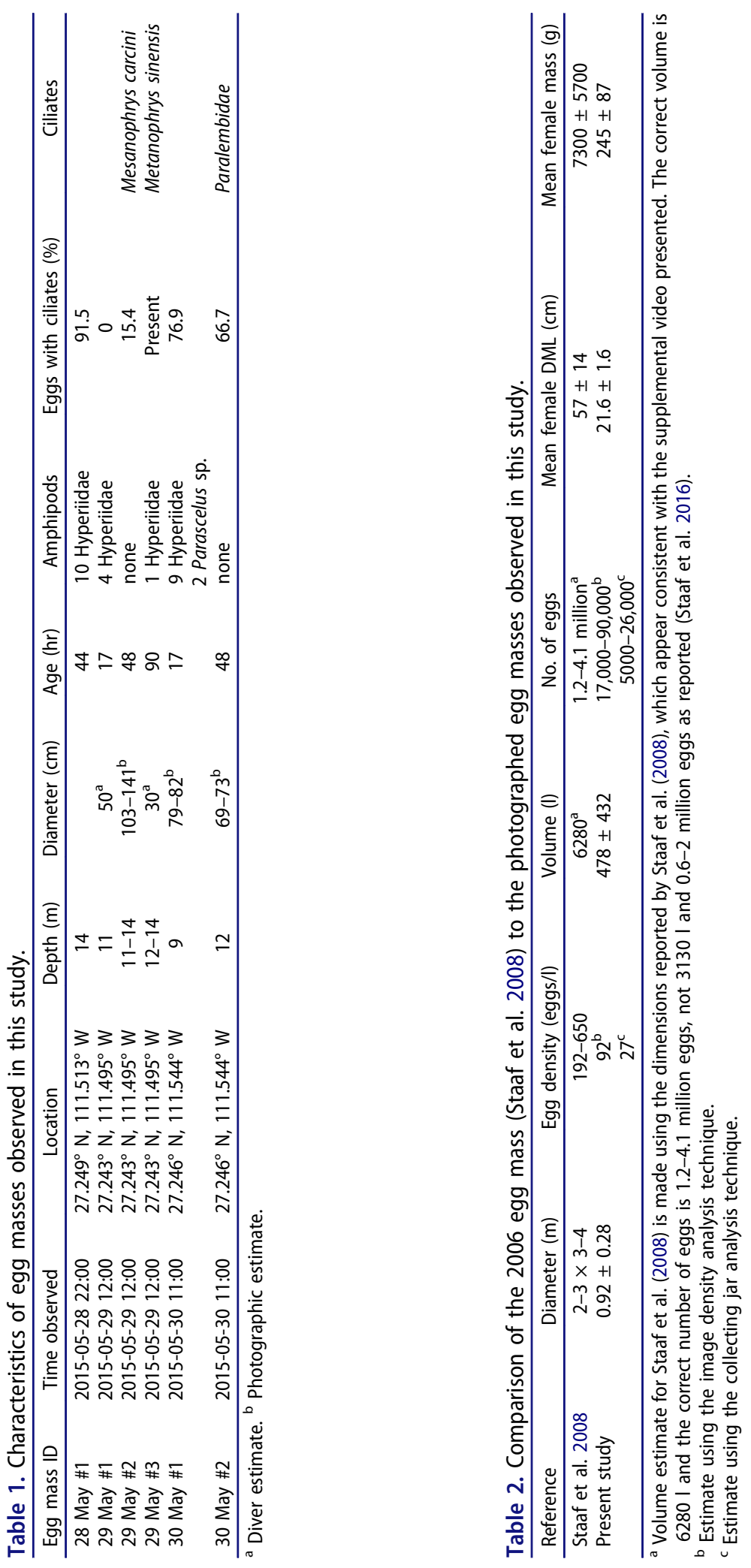

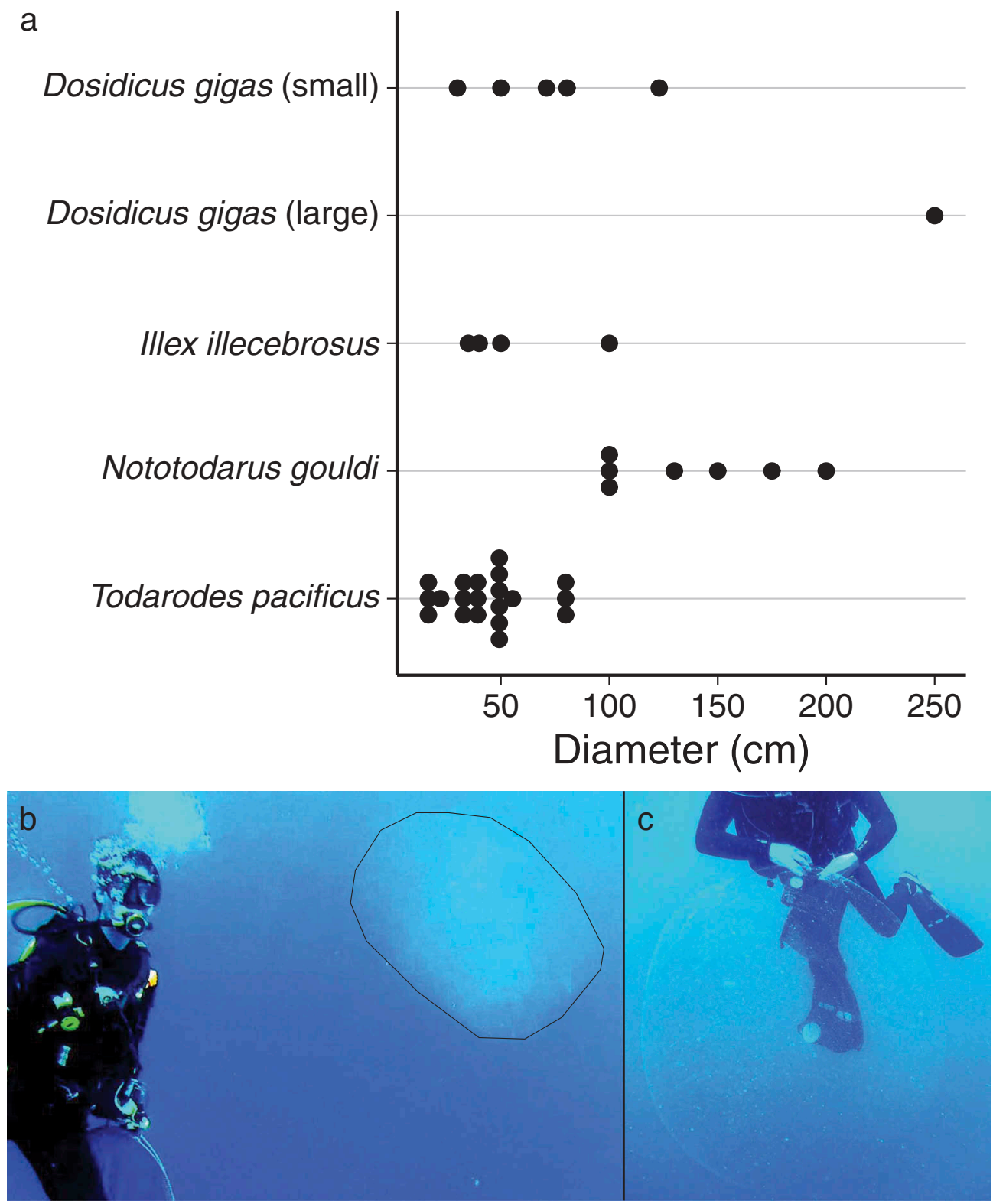

Figure 2. (a) Distribution of ommastrephid egg mass diameters. Dosidicus gigas (small) are from the present study. Dosidicus gigas (large) is from Staaf et al. (2008). Illex illecebrosus are from Durward et al. (1980) and O'Dor and Balch (1985). Nototodarus gouldi are from O'Shea et al. (2004). Todarodes pacificus are from Bower and Sakurai (1996) and Puneeta et al. (2015). (b) 80-cm egg mass (30 May \#1). (c) 122-cm egg mass (29 May \#2).

in diameter. The density of eggs was estimated to be 92 eggs/l jelly matrix using the image technique and 27 eggs/l using the collecting jar technique (Table 2). Assuming egg density is uniform within the egg mass (Staaf et al. 2008) and representative of all egg masses, the 
photographed egg masses contained 17,000-90,000 eggs each using the image technique, and 5000-26,000 eggs using the jar technique (Table 2).

The average size of females caught $(n=27)$ was $21.6 \pm 1.6 \mathrm{~cm}$ DML (Table 2). Although the maturity of all these females was not assessed, two Stage $V$ females were caught that measured 17.6 and $22.5 \mathrm{~cm}$ DML each, and a $23.2 \mathrm{~cm}$ DML female spawned an egg mass in captivity.

\section{Embryos and paralarvae}

Embryos within a single mass were at similar developmental stages and were in a headdown position. Among the egg masses, however, embryos were at notably different stages ranging from Stage 5 to young rhynchoteuthion paralarvae (Figure 3(a)). On 29 May, three egg masses were found on the same dive (41-minute duration) within tens of metres. The modal developmental stages of these three masses were Stage 13, Stage 17 and paralarvae. All six egg masses were found within $5 \mathrm{~km}$ of each other over the course of $<39$ hours. The mass with paralarvae had an opaque region along the bottom described by one diver as appearing 'torn'.

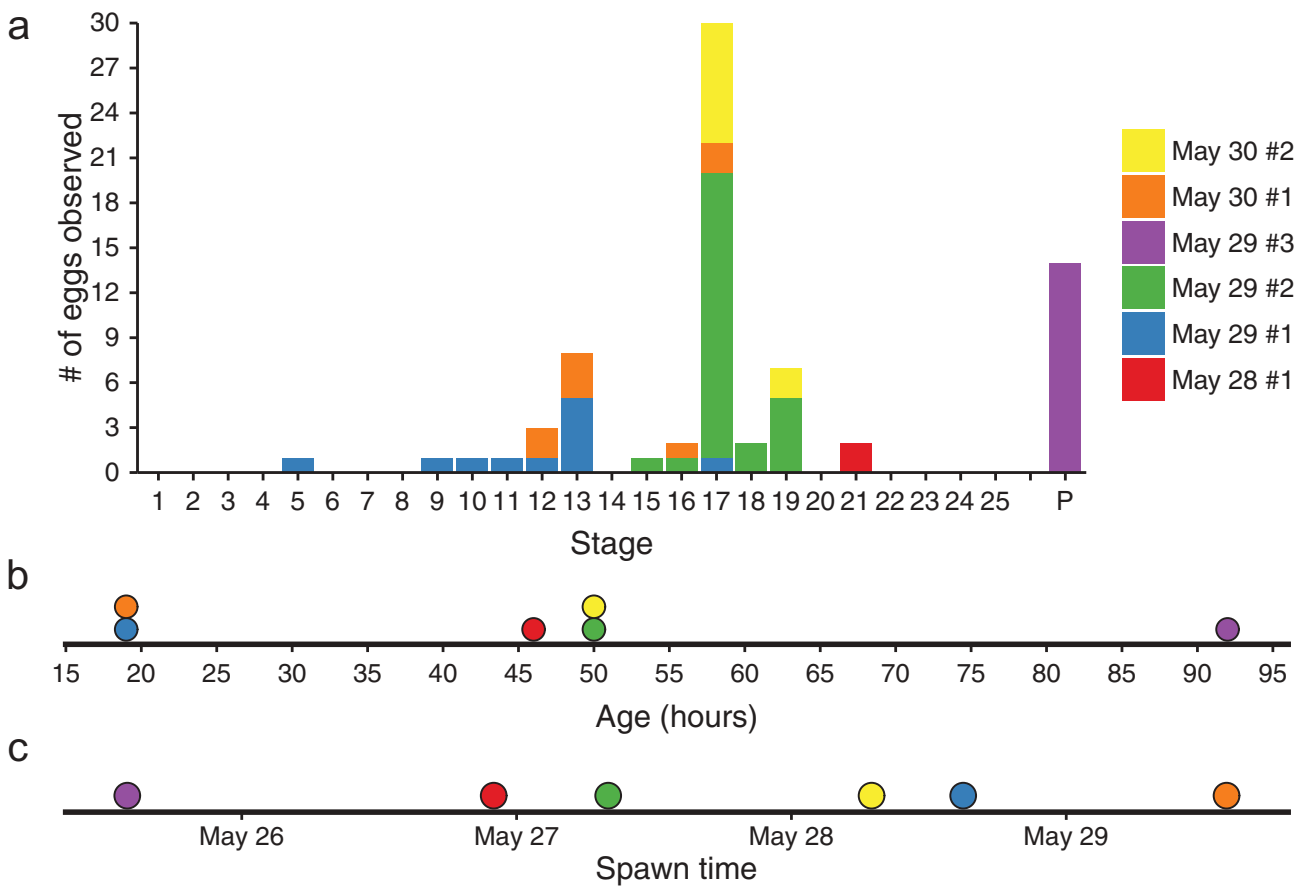

Figure 3. (a) Distribution of Dosidicus gigas embryo and paralarval stages found in six egg masses. The variability in the number of eggs from each mass was due to sampling variability. (b) Estimated age (duration since spawning event) of egg masses based on modal stage. Stages and corresponding ages are based on Watanabe et al. (1996). Note that the May 29 \#2 and May 30 \#2 masses are slightly older than May $28 \# 1$ even though they have less developed embryos because the Stage 17 age estimate is from 20 rather than $23^{\circ} \mathrm{C}$ incubation and thus a slower developmental rate. (c) Estimated time the egg masses were spawned based on age. 


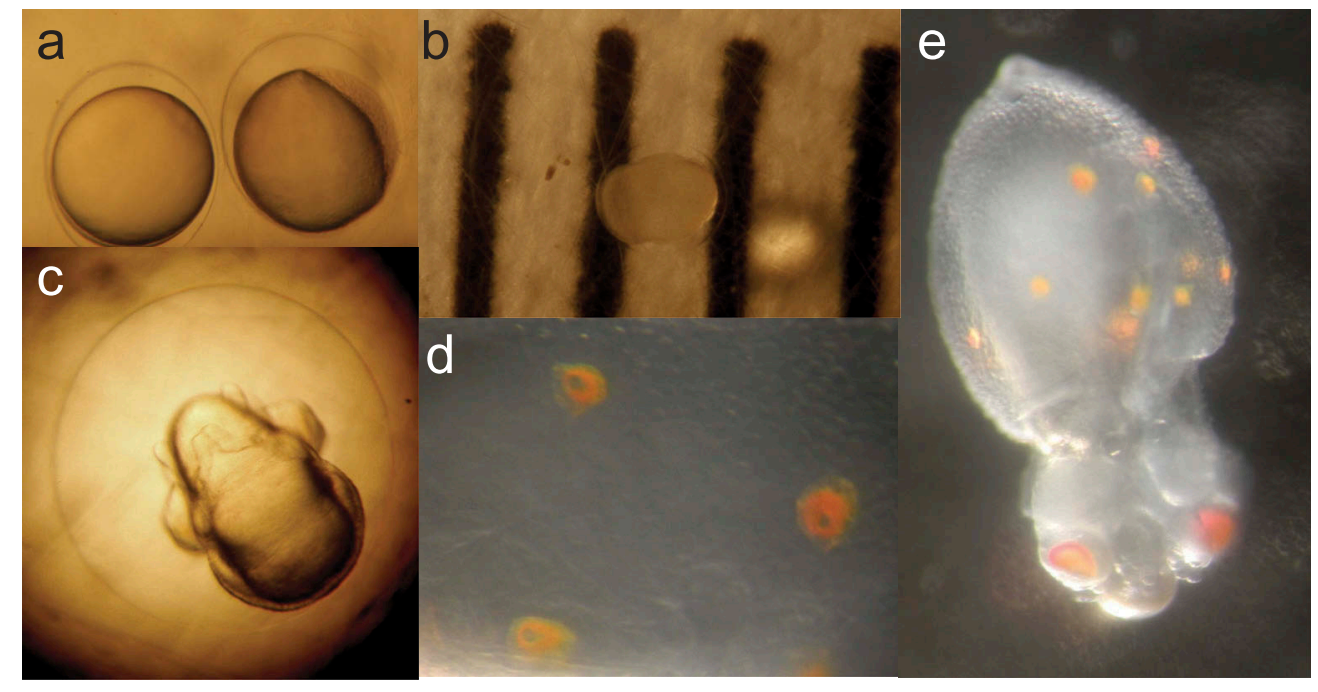

Figure 4. (a) Dosidicus gigas embryos. (b) Stage 17 embryo on a $1 \mathrm{~mm}$-spaced ruler. (c) Stage 21 embryo. (d) Punctate chromatophores on a paralarva. (e) Hatched paralarva. Note the very short proboscis.

Most hatched paralarvae (that were still within the egg mass) had a mantle contraction rate of $0.1-0.4 \mathrm{~Hz}$. They had two or three transverse rows of mantle chromatophores: the posterior row had three chromatophores on the ventral side, the middle row (when present) had one chromatophore on the ventral side, and the anterior row had six or more chromatophores around the entire mantle of the animal (Figure 4(e)). Some chromatophores were not uniformly pigmented, but rather were punctate, with a gap in the middle of the bright orange pigment granules of the sacculus (Cloney and Florey 1968) (Figure 4(d)).

Based on embryonic age estimates, the egg masses were 19-92 hours postfertilization and were spawned in a 5-day period between 25 May and 29 May 2015 (Figure 3(b,c)).

\section{Associated biota}

Five of the six egg masses contained ciliates that were concentrated around the embryos. Ciliate density around embryos ranged from one to hundreds per embryo. The extent of ciliate infestation varied greatly between the egg masses, from 15 to $92 \%$ of embryos examined. Embryos that had ciliates often had an opaque wrinkly white chorion, were missing the outer jelly layer, and were amorphous in shape (Figure 5(b)). Ciliates were often observed moving within 'tunnels' inside the embryonic tissue. One live paralarva was observed to have a single eye being 'swarmed' by ciliates (Figure 5(a)). Three species of scuticociliates were identified from three egg masses: Mesanophrys carcini (18S, 99\% match), Metanophrys sinensis (100\% match), and an unknown taxon (93\% match for Paralembidae).

Live hyperiid amphipods (Suborder Hyperiidea) were also observed in collecting jar samples of four of the six egg masses. At least three species were found, but genetic 


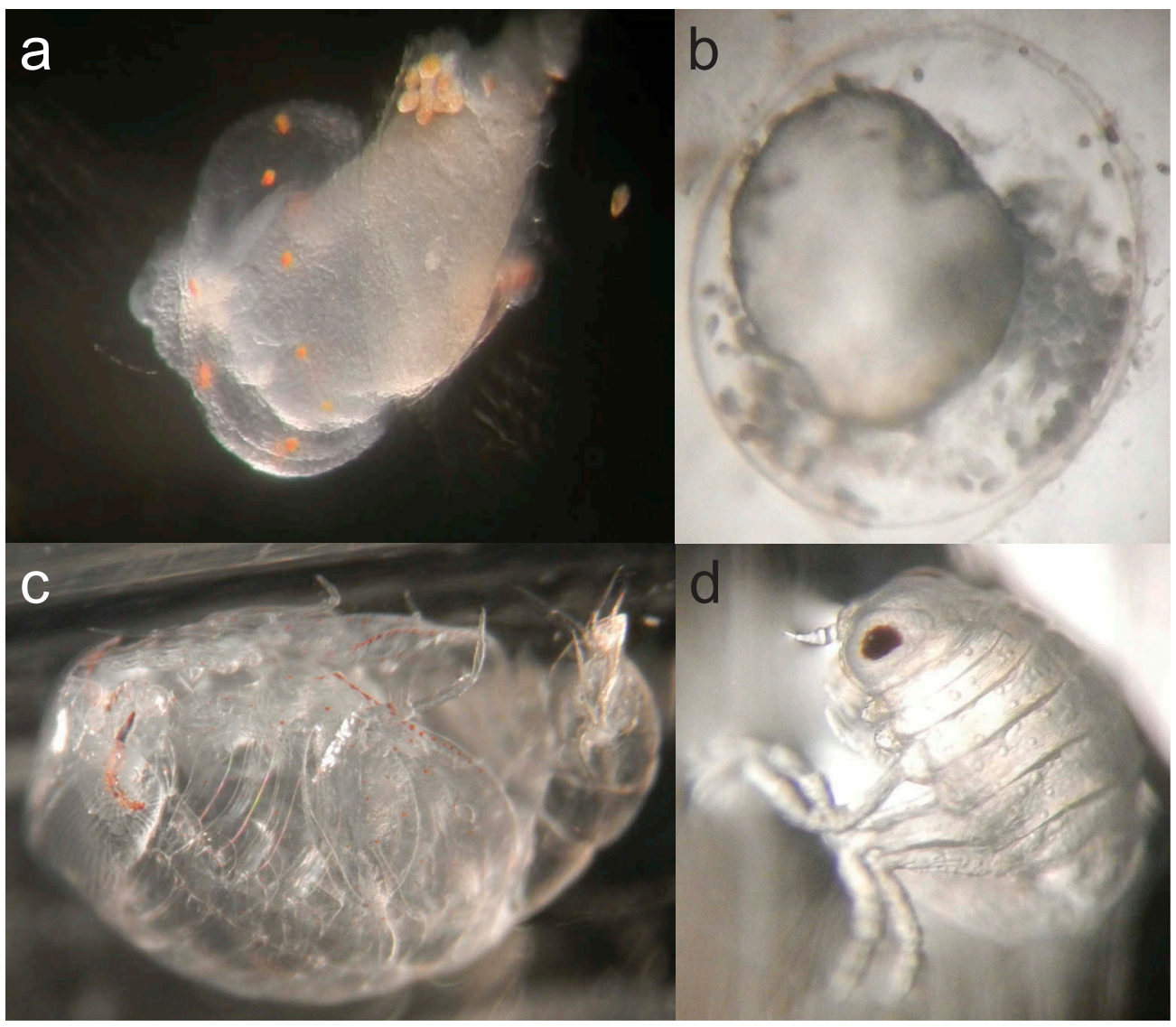

Figure 5. (a) Scuticociliates (Metanophrys sinensis) around the eye of a live Dosidicus gigas paralarva. (b) Scuticociliates around a dead embryo. (c) Parascelus sp. found in a D. gigas egg mass sample. (d) An amphipod (Hyperiidae) found in a $D$. gigas egg mass sample.

analyses were only conducted on one for which a specimen was preserved: Parascelus sp. (18S, 96\% match for Parascelus edwardsi), which occurred twice on one egg mass (Figure 5(c)). At least two species from the family Hyperiidae were identified from photographs. Twenty-four individuals from this family were found on four egg masses (Figure 5(d)).

\section{Discussion}

\section{Egg masses}

All the egg masses in this study were found at 9-14 $\mathrm{m}$ depth, between two thermoclines at 24 and $25^{\circ} \mathrm{C}$ (Figure 1). This is similar to the egg mass found by Staaf et al. (2008) and corroborates the experimental evidence that ommastrephid egg masses settle at pycnoclines (Puneeta et al. 2015). According to Staaf et al. (2011), D. gigas embryos successfully hatch at $25^{\circ} \mathrm{C}$ but not $30^{\circ} \mathrm{C}$ with developmental rate increasing with increasing temperature up to this maximum. Hence, the local temperature environment of the 
egg masses found here facilitated the fastest developmental rate within their thermal window.

The egg masses documented in this study (69-141 cm diameter) were smaller than that reported by Staaf et al. (2008) in June 2006. This resulted in egg number estimates one to two orders of magnitude lower. Our photographic estimate of egg density probably provided a more accurate measurement than our collecting jar estimate due to the challenge of filling a collecting jar with a representative sample of an egg mass. Hence, the difference in egg number estimates between this study and Staaf et al. (2008), which used the collecting jar technique, may be an underestimate. Even if the egg density were the same between the two studies, the smaller egg masses in this study were 13 times less fecund due to the size difference alone.

This difference in egg mass size is likely because the squid from the present study were small-sized, whereas squid from the 2006 study were large-sized (Arkhipkin et al. 2015). Egg mass size and egg number appear proportional to body size in D. gigas. Since egg masses are composed primarily of jelly from the nidamental glands (Kimura et al. 2004), it is to be expected that egg mass size scales with body size. Large-sized individuals have larger nidamental glands and probably more eggs in their oviducts than small-sized individuals, and so are able to produce more jelly (Markaida and SosaNishizaki 2001; Markaida 2006; Nigmatullin and Markaida 2009).

The scaling of potential fecundity (number of oocytes in ovaries) with body size has been well examined for D. gigas (Nigmatullin et al. 2001; Nigmatullin and Markaida 2009). The scaling of actual fecundity (number of eggs spawned over an individual's lifetime), however, requires knowledge of both the number of eggs in each mass (this study) and number of spawned masses by an individual female in her lifetime. Observations of spent females or comprehensive observations of a female's spawning history are still required to empirically estimate actual fecundity.

The egg masses documented here were similar in size to captively spawned $I$. illecebrosus, T. pacificus and wild N. gouldi and S. pteropus egg masses (Figure 2(a); O'Dor and Balch 1985; Laptikhovsky and Murzov 1990; O'Shea et al. 2004; Puneeta et al. 2015). The high variability in egg mass size in this study $(69-141 \mathrm{~cm})$ can be due to a number of factors, in addition to the variation in female size, including number of eggs in the oviducts, quantity of nidamental gland jelly, or interrupted spawning (Puneeta et al. 2015, 2016).

The El Niño Southern Oscillation is an important driver of interannual SST variability in the Gulf of California (Robles and Marinone 1987) and modulator of the population distribution of Dosidicus gigas size-at-maturity (Arkhipkin et al. 2015). The higher proportion of small-sized females maturing during an El Niño event will produce egg mass batches with fewer young.

\section{Embryos and paralarvae}

This study provides the first indication of the spatial and temporal variability of ommastrephid egg mass spawning activity in the wild. Egg masses were not observed during the first 8 days (13 dives) nor during the last 2 days (four dives) of on-site surveying. All six egg masses were observed during a 3-day window (on 
three of four dives). By comparing the embryo stages to the known developmental rate in T. pacificus (Watanabe et al. 1996), we estimated that the egg masses were spawned within a 5-day period (Figure 3(c)). This period may be shorter since the incubation temperature for these eggs was $4-5^{\circ} \mathrm{C}$ higher than the incubation temperature used by Watanabe et al. (1996). However, the time to hatching for D. gigas at $18^{\circ} \mathrm{C}$ is nearly twice as long as T. pacificus at $20^{\circ} \mathrm{C}$ (Staaf et al. 2011), so the ages estimated here may also be conservative. Most of the spawning time estimates were during the day, which contradicts observations in captivity that indicate ommastrephid squids tend to spawn at night or the early morning (von Boletzky et al. 1973; Chesalin and Giragosov 1993; Staaf et al. 2008). Furthermore, D. gigas are diel vertical migrators, typically inhabiting surface waters, where these egg masses were observed, only at night (Gilly et al. 2006; Seibel 2015). Regardless, it is very likely that these spawning events occurred within a few days.

The narrow observation window (3 days) within the broader search window (14 days) suggests that egg mass spawning activity is temporally and/or spatially patchy. The Gulf of California is a highly dynamic environment with constantly moving water masses (Robles and Marinone 1987; Kahru et al. 2004). Hence, the patchiness of our stationary observations may have been dominated by spatial rather than temporal variation in egg mass spawning events. Females may have spawned egg masses close to existing egg masses, a behaviour well documented in loliginid (Arnold 1962; Larcombe and Russell 1971) and sepiolid (Deickert and Bello 2005; Laptikhovsky et al. 2008) squids and cuttlefish (Hall and Hanlon 2002). Alternatively, as mature females were caught consistently throughout the 14-day search window but egg masses were only found on 3 days, there may be temporal patchiness to spawning activity as well.

All sampling in this study was done at one spatial location $(<5 \mathrm{~km}$ range) within Guaymas Basin in the Gulf of California. Further studies examining egg masses at other locations within the Gulf of California and the Eastern Tropical Pacific would be helpful for determining how representative the spatial and temporal variability of egg masses observed here is for the entire $D$. gigas population. One egg mass contained hatched paralarvae, and it was the only mass that had an opaque region along the bottom of the mass, described by one diver as appearing 'torn'. This may be similar to the 'whitish strands' described by Staaf et al. (2008) in an egg mass that contained Stage 25 embryos. Both of these egg masses were near the end of their lifespan. Hence, the white opaque regions may be areas of disintegration (Pandey Puneeta, pers. comm.).

Although the absolute age of the paralarvae found on 29 May is unknown, they had a notably shorter proboscis (fused tentacles) than the 3- to 6-day-old paralarvae observed by Staaf et al. (2008) or the 1- to 4-day-old paralarvae raised by Yatsu et al. (1999) at cooler temperatures. As proboscis length increases with age, this suggests that the present paralarvae were younger, perhaps less than 1 day post hatching. Todarodes pacificus paralarvae hatching from captively spawned egg masses only spent about 2 hours in the egg mass before swimming out towards the surface (Puneeta et al. 2015). The paralarvae in the present study, however, may not have been healthy, as indicated by their very low mantle contraction rates $(0.1-0.4 \mathrm{~Hz}$ versus $2.2-4.2 \mathrm{~Hz}$ in healthy newly hatched paralarvae; Staaf et al. 2008). It is possible that other healthy paralarvae hatched and had left the egg mass before we found it. 
The timing of chromatophore pattern development in embryos and paralarvae observed here differed from the patterns on other ommastrephid squids. For example, in T. pacificus, two rows of chromatophores first develop on the anterior mantle at Stage 21 (Watanabe et al. 1996), but chromatophores were not yet developed in Stage 21 D. gigas (Figure 4(c)). Furthermore, the hatched D. gigas paralarvae in this study had two to three rows of chromatophores, a pattern intermediate between the patterning of embryonic $T$. pacificus stages 21 and 22, which are still 1-2 days from hatching. This relatively delayed chromatophore development has been documented previously. Far fewer chromatophores were present on 6-day old D. gigas paralarvae than on 5-day-old I. illecebrosus paralarvae that were incubated in $5^{\circ} \mathrm{C}$ cooler seawater (Durward et al. 1980; Yatsu et al. 1999).

\section{Associated biota}

The nidamental jelly that composes ommastrephid egg masses has typically been considered an effective guard against predators and parasites ranging from bacteria, protozoans and fungi to crustaceans and fishes (Bower and Sakurai 1996; O'Shea et al. 2004; Staaf et al. 2008). Our finding of both ciliate and amphipod taxa casts doubt on the effectiveness of the jelly for deterring all biota.

Ciliate contamination has been reported before for Illex illecebrosus egg masses held in captivity (Durward et al. 1980). Ciliates were observed living on non-viable embryos in 'high concentrations'. Our study demonstrates that ciliate contamination is not an artefact of captivity, but a naturally occurring phenomenon in ommastrephid squid egg masses. Upon hatching, paralarvae may consume ciliates as a food source by aggregating ciliates and other microbes in the mucus coating their body surface (Vidal and Haimovici 1998). For newly hatched paralarvae who are not yet able to actively capture prey, ciliates may be an important food source. Hence ciliate infestation in the egg mass may be an early food source for hatchlings.

However, the scuticociliate clade found on these egg masses is different from most bacteriophagous ciliates (Sherr and Sherr 1987) in that some species are histophagous, or tissue eating. Mesanophrys, one of the genera found in this study, are known parasites of crustaceans (Messick and Small 1996; Morado et al. 1999). Scuticociliates are only facultative parasites, so we are unable to distinguish whether they had a pre-mortality negative impact on embryos or if they were feeding on bacterial growth around decomposing embryonic tissue. Manipulative experiments examining the effect of ciliate presence on embryonic mortality would be helpful for clarifying this interaction. It is unknown whether the ciliate source is from the seawater used in forming the egg mass, the female's reproductive tract, or ambient seawater during embryonic incubation.

One of the three amphipod taxa found on egg masses in this study, Parascelus sp., are known parasites of siphonophores in the Gulf of California (Gasca and Haddock 2004). Hyperiid amphipods, including members of the family Hyperiidae that were found on the majority of egg masses, are frequent parasites of gelatinous zooplankton (Dahl 1959; Boonstra et al. 2015), which could include squid egg masses in this region. 
To our knowledge, this is the first documentation of biota associated with wild ommastrephid egg masses. Parasites can affect population dynamics of cephalopods (Pascual et al. 2007) and have been shown to lead to economic losses for ommastrephid fisheries (Pascual et al. 1998).

\section{Acknowledgments}

We would like to thank Tracy Shaw, Erin L. McLean, Ann Kelly, Jillon McGreal, Leanne Elder and Pandey Puneeta for their assistance in the field, laboratory and in preparation of this manuscript. We thank two anonymous reviewers for helpful comments on the manuscript. We thank the captain and crew of the R/V Oceanus for their assistance at sea.

\section{Disclosure statement}

No potential conflict of interest was reported by the authors.

\section{Funding}

This work was supported by the Division of Biological Infrastructure [0215393]; Division of Emerging Frontiers [1316113] to BAS; Division of Graduate Education [1244657] to MAB; Office of Experimental Program to Stimulate Competitive Research [0554548,1004057]; U.S. Department of Agriculture [2002-34438-12688,2003-34438-13111].

\section{ORCID}

Matthew A. Birk (1) http://orcid.org/0000-0003-0407-4077

Christopher Paight (D) http://orcid.org/0000-0001-9051-5021

Brad A. Seibel (D) http://orcid.org/0000-0002-5391-0492

\section{References}

Abràmoff MD, Magalhães PJ, Ram SJ. 2004. Image processing with ImageJ. Biophotonics Int. 11:36-41.

Arkhipkin A, Argüelles J, Shcherbich Z, Yamashiro C. 2015. Ambient temperature influences adult size and life span in jumbo squid (Dosidicus gigas). Can J Fish Aquat Sci. 72:400-409.

Arkhipkin Al. 1992. Reproductive system structure, development and function in cephalopods with a new general scale for maturity stages. J Northwest Atl Fish Sci. 12:63-74.

Arnold JM. 1962. Mating behavior and social structure in Loligo pealii. Biol Bull. 123:53-57.

Boonstra JL, Koneval ME, Clark JD, Schick M, Smith M, Stark AL. 2015. Milbemycin oxime (Interceptor) treatment of amphipod parasites (Hyperiidae) from several host jellyfish species. J Zoo Wildl Med. 46:158-160.

Bower JR, Sakurai Y. 1996. Laboratory observations on Todarodes pacificus (Cephalopoda: Ommastrephidae) egg masses. Am Malacol Bull. 13:65-71.

Chesalin MV, Giragosov V. 1993. The egg mass and embryonic development of the purple squid Sthenoteuthis oualaniensis (the gigantic Arabian form) under experimental conditions. Oceanology. 33:116-120.

Chin TM, Vazquez J, Armstrong E. 2013. A multi-scale, high-resolution analysis of global sea surface temperature. Algorithm Theor Basis Doc Version. 1:13.

Cloney RA, Florey E. 1968. Ultrastructure of cephalopod chromatophore organs. Z Zellforsch Mikrosk Anat. 89:250-280. 
d'Orbigny AD. 1835. Voyage dans I'Amérique Méridionale. Paris: Chez Pitois-Levrault. 5:1-758.

Dahl E. 1959. The amphipod, Hyperia galba, an ectoparasite of the jelly-fish, Cyanea capillata. Nature. 183:1749.

Deickert A, Bello G. 2005. Egg masses of Sepietta oweniana (Cephalopoda: Sepiolidae) collected in the Catalan Sea. Sci Mar. 69:205-209.

Durward RD, Vessey E, O'Dor RK, Amaratunga T. 1980. Reproduction in the squid, Illex illecebrosus: first observations in captivity and implications for the life cycle. Int Comm Northwest Atl Fish Sel Pap. 6:6-13.

Folmer O, Black M, Hoeh W, Lutz R, Vrijenhoek R. 1994. DNA primers for amplification of mitochondrial cytochrome $\mathrm{c}$ oxidase subunit I from diverse metazoan invertebrates. Mol Mar Biol Biotechnol. 3:294-299.

Gasca R, Haddock SHD. 2004. Associations between gelatinous zooplankton and hyperiid amphipods (Crustacea: Peracarida) in the Gulf of California. Hydrobiologia. 530-531:529-535.

Gilly WF, Markaida U, Baxter CH, Block BA, Boustany A, Zeidberg LD, Reisenbichler K, Robison BH, Bazzino G, Salinas C. 2006. Vertical and horizontal migrations by the jumbo squid Dosidicus gigas revealed by electronic tagging. Mar Ecol Prog Ser. 324:1-17.

Haddock SHD, Heine JN. 2005. Scientific blue-water diving. La Jolla (CA): California Sea Grant College Program.

Hall KC, Hanlon RT. 2002. Principal features of the mating system of a large spawning aggregation of the giant Australian cuttlefish Sepia apama (Mollusca: Cephalopoda). Mar Biol. 140:533-545.

Hamabe M. 1963. Spawning experiments of the common squid, Ommastrephes sloani pacificus Steenstrup, in an indoor aquarium. Bull Japanese Soc Sci Fish. 29:930-934.

Ito A, Wada H, Aoki MN. 2008. Phylogenetic analysis of caprellid and corophioid amphipods (Crustacea) based on the 18S rRNA gene, with special emphasis on the phylogenetic position of Phtisicidae. Biol Bull. 214:176-183.

Jereb P, Roper CFE, editors. 2010. Cephalopods of the world. An annotated and illustrated catalogue of cephalopod species known to date. Volume 2. Myopsid and Oegopsid Squids. 4th ed. Rome: FAO.

Kahru M, Marinone SG, Lluch-Cota SE, Parés-Sierra A, Mitchell BG. 2004. Ocean-color variability in the Gulf of California: scales from days to ENSO. Deep Res Part II Top Stud Oceanogr. 51:139-146.

Kimura S, Higuchi Y, Aminaka M, Bower JR, Sakurai Y. 2004. Chemical properties of egg-mass mucin complexes of the ommastrephid squid Todarodes pacificus. J Molluscan Stud. 70:117-121.

Laptikhovsky VV, Murzov SA. 1990. Epipelagic egg mass of the squid Sthenoteuthis pteropus collected in the tropical eastern Atlantic. Biol Morya. 3:62-63.

Laptikhovsky VV, Nigmatullin CM, Hoving HJT, Onsoy B, Salman A, Zumholz K, Shevtsov GA. 2008. Reproductive strategies in female polar and deep-sea bobtail squid genera Rossia and Neorossia (Cephalopoda: Sepiolidae). Polar Biol. 31:1499-1507.

Lara E, Berney C, Harms H, Chatzinotas A. 2007. Cultivation-independent analysis reveals a shift in ciliate $18 \mathrm{~S}$ rRNA gene diversity in a polycyclic aromatic hydrocarbon-polluted soil. FEMS Microbiol Ecol. 62:365-373.

Larcombe MF, Russell BC. 1971. Egg laying behaviour of the broad squid, Sepioteuthis bilineata. New Zeal J Mar Freshw Res. 5:3-11.

Markaida U. 2006. Population structure and reproductive biology of jumbo squid Dosidicus gigas from the Gulf of California after the 1997-1998 El Nino event. Fish Res. 79:28-37.

Markaida U, Sosa-Nishizaki O. 2001. Reproductive biology of jumbo squid Dosidicus gigas in the Gulf of California, 1995-1997. Fish Res. 54:63-82.

Messick GA, Small EB. 1996. Mesanophrys chesapeakensis n. sp., a histophagous ciliate in the blue crab, Callinectes sapidus, and associated histopathology. Invertebr Biol. 115:1-12.

Morado JF, Giesecke RH, Syrjala SE. 1999. Molt related mortalities of the Dungeness crab Cancer magister caused by a marine facultative ciliate Mesanophrys pugettensis. Dis Aquat Org. 38:143-150.

Naef A. 1928. Die Cephalopoden (Embryologie). Fauna Flora Golf Neapel. 35:1-357. 
Nigmatullin CM, Markaida U. 2009. Oocyte development, fecundity and spawning strategy of large sized jumbo squid Dosidicus gigas (Oegopsida: Ommastrephinae). J Mar Biol Assoc United Kingdom. 89:789-801.

Nigmatullin CM, Nesis KN, Arkhipkin Al. 2001. A review of the biology of the jumbo squid Dosidicus gigas (Cephalopoda: Ommastrephidae). Fish Res. 54:9-19.

O'Dor RK, Balch N. 1985. Properties of Illex illecebrosus egg masses potentially influencing larval oceanographic distribution. Northwest Atl Fish Organ Sci Counc Stud. 9:69-76.

O'Dor RK, Balch N, Foy EA, Hirtle RWM, Johnston DA. 1982. Embryonic development of the squid, Illex illecebrosus, and effect of temperature on development rates. J Northwest Atl Fish Sci. 3:41-45.

O'Shea S, Bolstad KS, Ritchie PA. 2004. First records of egg masses of Nototodarus gouldi McCoy, 1888 (Mollusca: Cephalopoda: Ommastrephidae), with comments on egg-mass susceptibility to damage by fisheries trawl. New Zeal J Zool. 31:161-166.

Pascual S, González Á, Guerra Á. 2007. Parasites and cephalopod fisheries uncertainty: towards a waterfall understanding. Rev Fish Biol Fish. 17:139-144.

Pascual S, González ÁF, Guerra Á. 1998. Effect of parasitism on the productivity of the ommastrephid stocks in Galician waters (NW Spain): economic loss. Iberus. 16:95-98.

Puneeta P, Vijai D, Yoo H-K, Matsui H, Sakurai Y. 2015. Observations on the spawning behavior, egg masses and paralarval development of the ommastrephid squid Todarodes pacificus in a laboratory mesocosm. J Exp Biol. 218:3825-3835.

Puneeta P, Vijai D, Yamamoto J, Sakurai Y. 2016. Male copulatory behavior interrupts Japanese flying squid Todarodes pacificus female spawning activity. Mar Ecol Prog Ser. 551:277-281.

Robles JM, Marinone SG. 1987. Seasonal and interannual thermohaline variability in the Guaymas Basin of the Gulf of California. Cont Shelf Res. 7:715-733.

Seibel BA. 2015. Environmental physiology of the jumbo squid, Dosidicus gigas (d'Orbigny, 1835) (Cephalopoda: Ommastrephidae): implications for changing climate. Am Malacol Bull. 33:161-173.

Sherr EB, Sherr BF. 1987. High rates of consumption of bacteria by pelagic ciliates. Nature. 325:710-711.

Staaf DJ, Camarillo-Coop S, Haddock SHD, Nyack AC, Payne J, Salinas-Zavala CA, Seibel BA, Trueblood L, Widmer C, Gilly WF. 2016. Natural egg mass deposition by the Humboldt squid (Dosidicus gigas) in the Gulf of California and characteristics of hatchlings and paralarvae ERRATUM. J Mar Biol Assoc United Kingdom. CJO2016. doi:10.1017/S0025315416000266

Staaf DJ, Camarillo-Coop S, Haddock SHD, Nyack AC, Payne J, Salinas-Zavala CA, Seibel BA, Trueblood L, Widmer C, Gilly WF. 2008. Natural egg mass deposition by the Humboldt squid (Dosidicus gigas) in the Gulf of California and characteristics of hatchlings and paralarvae. J Mar Biol Assoc United Kingdom. 88:759-770.

Staaf DJ, Zeidberg LD, Gilly WF. 2011. Effects of temperature on embryonic development of the Humboldt squid Dosidicus gigas. Mar Ecol Prog Ser. 441:165-175.

Vidal ÉAG, Haimovici M. 1998. Feeding and the possible role of the proboscis and mucus cover in the ingestion of microorganisms by rhynchoteuthion paralarvae (Cephalopoda: Ommastrephidae). Bull Mar Sci. 63:305-316.

von Boletzky S, Rowe L, Aroles L. 1973. Spawning and Development of the Eggs, in the Laboratory, of Illex coindetii. Veliger. 15:257-258.

Watanabe K, Sakurai Y, Segawa S, Okutani T. 1996. Development of the ommastrephid squid Todarodes pacificus, from fertilized egg to rhynchoteuthion paralarva. Am Malacol Bull. 13:73-88.

Yatsu A, Tafur R, Maravi C. 1999. Embryos and rhynchoteuthion paralarvae of jumbo flying squid Dosidicus gigas (Cephalopoda) obtained through artificial fertilization from Peruvian waters. Fish Sci. 65:904-908. 


\section{Appendix}

Primers used for DNA amplification

Squid COX1 primers (Folmer et al. 1994)

LCO_1490

GGTCAACAAATCATAAAGATATTGG

HCO_2198

TAAACTTCAGGGTGACCAAAAAATCA

Amphipod 185 primers (Ito et al. 2008)

Amphipod $18 \mathrm{~F}$

CCTACCTGGTTGATCCTGCCAGT

Amphipod 18R

TAATGATCCTTCCGCAGGTT

Ciliate 185 primers (Lara et al. 2007)

Cil-f

TGGTAGTGTATTGGACWACCA

cil-r1

TCTGATCGTCTTTGATCCCTTA

$1391 \mathrm{~F}$

GTACACACCGCCCGTC

EukB

TGATCCTTCTGCAGGTTCACCTAC 